10

\title{
Экспериментальные исследования различных полимерных композиций для создания рельефно-фазовых дифракционных решеток для систем дополненной реальности
}

\author{
(C) А.Б. Соломашенко, Г.К. Красин, Е.А. Дроздова
}

Московский государственный технический университет им. Н.Э. Баумана, 105005 Москва, Россия

e-mail: art_87@mail.ru

Поступила в редакцию 15.01.2020 г.

В окончательной редакции 23.03.2020 г.

Принята к публикации 28.03.2020 г.

Показана возможность копирования высокочастотных дифракционных решеток, полученных в слое фоторезиста, на стеклянные подложки с помощью полимерных композиций (ОКМ и Техновит) и проведен их сравнительный анализ. В основе механизма копирования рельефно-фазовой структуры лежит двухэтапный процесс, заключающийся в получении никелевой мастер-детали с последующим нанесением на нее полимерной композиции и ее отверждением под воздействием УФ излучения. Осуществлена оптимизация режимов копирования (время, экспозиция, толщина полимерной основы), что позволило получить рельефнофазовые дифракционные решетки с глубиной поверхностного рельефа, сопоставимой с исходной структурой, полученной в слое фоторезиста. Проведена оценка дифракционной эффективности полученных решеток, а также оценка изменения глубины поверхностного рельефа полимерных копий, полученных с одной мастердетали.

Ключевые слова: рельефно-фазовая дифракционная решетка, полимерная композиция, глубина рельефа, дифракционная эффективность.

DOI: $10.21883 / O S .2020 .07 .49563 .110-20$

\section{Введение}

Такие рельефно-фазовые структуры, как дифракционные оптические элементы (ДОЭ), в последнее время все чаще применяются для замены элементов физической оптики [1-4]. Одной из сфер их применения являются устройства дополненной реальности, современные тенденции развития которых связаны с разработкой различных вариантов структуры ДОЭ для световодных пластин [5-7]. В большинстве своем это ДОЭ с поверхностным рельефом, причем оптимизация различных параметров такой структуры (скважность дифракционной решетки, показатель преломления, глубина поверхностного рельефа, углы наклона и период) позволяет достичь наилучших значений по угловому полю зрения, цветности и равномерности яркости изображения дополненной реальности [5].

Для изготовления таких элементов применяются методы аналоговой голографии [7], а также электроннолучевой или нанопечатной [5] литографии. Литографические методы получения являются дорогостоящими и длительными по времени изготовления. В отличие от них метод аналоговой голографии, конечно, не обеспечивает получения требуемых вариантов структуры (в первую очередь, различные углы наклона профиля) ДОЭ, но является более доступным и производительным. При этом для каждого из вышеперечисленных методов задача копирования поверхностного рельефа является актуальной.

Одним из методов копирования рельефно-фазовых ДОЭ является изготовление металлической мастердетали и ее дальнейшее эмбоссирование [8] или нанесение на мастер-деталь полимерной композиции с ее отверждением под воздействием УФ излучения $[9,10]$. Отличительной особенностью ДОЭ для световодных пластин является достаточно высокая пространственная частота (от 1400 до $2800 \mathrm{~mm}^{-1}$ ) [7], необходимая для ввода излучения в пластину под углами, превышающими угол полного внутреннего отражения (ПВО). В процессе копирования это может привести к существенному уменьшению глубины поверхностного рельефа (а значит, уменьшению дифракционной эффективности) или вызвать невозможность копирования в принципе. Поэтому эксперименты по копированию дифракционных решеток с помощью полимерных композиций, описанные в настоящей работе, являются актуальными, поскольку могут применяться для получения дифракционных элементов на световодных пластинах, использующихся в системах дополненной реальности.

\section{Эксперимент}

В качестве объекта исследования были выбраны дифракционные решетки с пространственной частотой $1450 \mathrm{~mm}^{-1}$, полученные на слое фоторезиста марки 
Таблица 1. Зависимость глубины поверхностного рельефа от времени экспонирования дифракционной решетки

\begin{tabular}{c|c|c|c|c|c}
\hline \multicolumn{2}{c|}{ Время экспонирования, s } & 9 & 18 & 36 & 45 \\
\hline \multirow{5}{*}{ Глубина рельефа, nm } & Образец 1 & 40 & 100 & 221 & 327 \\
\cline { 2 - 6 } & Образец 2 & 46 & 106 & 231 & 336 \\
\cline { 2 - 6 } & Образец 3 & 49 & 108 & 237 & 348 \\
\cline { 2 - 6 } & Образец 4 & 52 & 115 & 224 & 365 \\
\cline { 2 - 6 } & Образец 5 & 43 & 113 & 218 & 375 \\
\hline \multicolumn{2}{|c|}{ Средняя глубина рельефа, nm } & 46 & 108.4 & 226.2 & 350.2
\end{tabular}

Таблица 2. Глубина поверхностного рельефа дифракционных решеток (в $\mathrm{nm})$, полученных на различных носителях

\begin{tabular}{c|c|c}
\hline Мастер-деталь & ОКМ (копия 1) & Техновит (копия 1) \\
\hline 50 & 31 & 32 \\
53 & 36 & 41 \\
57 & 47 & 43 \\
108 & 75 & 64 \\
109 & 78 & 67 \\
117 & 82 & 75 \\
204 & 160 & 103 \\
207 & 174 & 105 \\
220 & 181 & 110
\end{tabular}

S1813 толщиной около $1 \mu \mathrm{m}$. Решетки были получены на площади $1 \mathrm{~cm}^{2}$ методом голографической записи по симметричной схеме с помощью Не-Cd-лазера с длиной волны $0.44 \mu \mathrm{m}$ и мощностью $100 \mu \mathrm{W}$. Глубина поверхностного рельефа дифракционной решетки может регулироваться или временем экспонирования, или временем проявления. Так как проявление происходит вручную и длится от 7 до $10 \mathrm{~s}$, то необходимая глубина рельефа обеспечивается подбором времени экспонирования, которое отрабатывается автоматически с помощью затвора. Глубина поверхностного рельефа дифракционных решеток измерялась с помощью атомносилового микроскопа Solver Pro, а результаты измерения представлены в табл. 1 .

Далее с полученных на слое фоторезиста дифракционных решеток глубиной порядка 50, 100 и $200 \mathrm{~nm}$ методом гальванического копирования были получены мастер-детали. Мастер-деталью является никелевая копия, представляющая собой лист толщиной $50 \mu \mathrm{m} \mathrm{c}$ матрицей дифракционных решеток. Использование в качестве носителя никелевой матрицы существенно увеличивает количество снятых копий, при этом появляется возможность обрабатывать поверхность мастер-детали ацетоном для удаления остатков жидкого и отвержденного полимера.

Порядок работы по получению полимерной копии заключался в следующем.
1. Изготовление формы для заливки полимерной композиции. Форма задаёт вид и размер будущих полимерных копий. Внутренний размер формы должен быть таким, чтобы в него полностью помещалась дифракционная решетка, предназначенная для копирования, внешний размер должен быть достаточно большим, чтобы обеспечить хорошее прилегание к мастер-детали и устойчивость конструкции, толщина формы отвечает за конечную толщину полимерной копии. Для получения копий использовалась форма для заливки из силикона.

2. Приготовление фотополимерной композиции. Композиция готовится непосредственно перед использованием. В стеклянном стаканчике взвешивается необходимое количество олигомера, далее к нему добавляется фотоинициатор в количестве $1 \%$ от массы олигомера (т.е. на $100 \mathrm{~g}$ олигомера требуется $1 \mathrm{~g}$ фотоинициатора). Компоненты тщательно перемешиваются. При перемешивании образуются пузыри, поэтому перед заливкой композицию необходимо выдержать некоторое время для выхода пузырей на поверхность. Для ускорения процесса стаканчик с композицией можно поместить в стакан с тёплой водой.

3. Изготовление полимерной копии. Поверхность мастер-детали должна быть чистая, сухая, обезжиренная. На никелевую мастер-деталь помещается силиконовая форма. Фотополимерная композиция заливается в полученную полость. Сверху кладётся чистое, обезжиренное стекло. Важно, чтобы при этом не произошло образование пузырей. Далее через верхнее стекло производится облучение ультрафиолетовым излучением. Время экспонирования определялось экспериментально, учитывая мощность излучения и толщину будущей фотополимерной копии.

В качестве полимерных композиций в эксперименте использовались композиции ОКМ и Техновит. Полимерная композиция ОКМ состоит из двух компонентов: олигомера (бис-(метакрилоксиэтиленкарбонат)диэтиленгликоля) и фотоинициатора (дифенил (2,4,6триметилбензоил) фосфиноксид и 2-ОН-2 метилпропиофенон в соотношении $1: 1$ ). Время воздействия (экспонирования) ультрафиолетовым излучением составило $24 \mathrm{~min}$ для толщины полимерного слоя $3 \mathrm{~mm}$ при мощности примерно $1.5 \mu \mathrm{J} / \mathrm{s} \cdot \mathrm{cm}^{2}$ (меньшее время экспонирования не обеспечивает достаточной полимеризации композиции), $8 \mathrm{~min}$ для толщины $1 \mathrm{~mm}$ и около $3 \mathrm{~min}$ для толщины порядка $0.2-0.3 \mathrm{~mm}$.

Полимерная композиция Техновит в процессе копирования наносится кисточкой тонким слоем на мастердеталь, а сверху накрывается покровным стеклом. Время экспонирования композиции Техновит составляло $8 \mathrm{~min}$ для толщины порядка $0.2-0.3 \mathrm{~mm}$. После экспонирования образовывался тонкий слой, который отделялся от никелевой мастер-детали, но оставался прикреплённым к стеклу. Адгезия к стеклу у композиции Техновит лучше, чем у ОКМ. При этом толщина полимерного слоя должна быть небольшой, т.е. до нескольких сотен 
$\mu \mathrm{m}$, так как при толщине копии около $1 \mathrm{~mm}$ и выше она становится не прозрачной, а мутной.

После проведения копирования дифракционных решеток с помощью полимерных композиций ОКМ и Техновит измерялись глубина поверхностного рельефа и дифракционная эффективность решеток. Глубина рельефа определялась с помощью атомно-силового микроскопа Solver Pro как полный перепад между вершинами и впадинами, а затем сравнивалась с глубиной поверхностного рельефа исходной решетки, полученной на слое фоторезиста, и мастер-детали, т. е. ее никелевой копии. Дифракционная эффективность определялась как отношение интенсивности пучка первого порядка дифракции, прошедшего через голограмму, к интенсивности падающего пучка для длины волны $0.52 \mu \mathrm{m}$.

\section{Результаты}

В качестве исходных дифракционных решеток использовались решетки с глубиной поверхностного рельефа 50, 100 и $200 \mathrm{~nm}$. Для каждой решетки была получена никелевая мастер-деталь, с которой, в свою очередь, были сняты полимерные копии.

Глубина поверхностного рельефа решеток приведена в табл. 2. Как видно из табл. 2, в случае применения всех полимерных композиций (ОКМ и Техновит) глубина поверхностного рельефа отличается от мастер-детали. В случае композиций ОКМ глубина рельефа примерно в 1.4-1.5 раза меньше, чем у оригинала, а в случае композиции Техновит глубина рельефа копии заметно меньше, чем у мастер-детали (например, для глубины рельефа $200 \mathrm{~nm}$ почти вдвое меньше). Таким образом, для эффективного копирования дифракционных решеток из двух описанных полимерных композиций больше подходит композиция ОКМ.

При этом высокая адгезия к стеклу композиции Техновит позволяет получать тонкие полимерные копии рельефно-фазовых решеток на стеклянных подложках, в том числе световодных, т. е. тех, которые используются в устройствах дополненной реальности. Данные стеклянные подложки могут иметь произвольную толщину (от $0.8 \mathrm{~mm}$ и выше) и показатель преломления, а также предварительно нанесенное покрытие, что важно для таких систем. При этом следует отметить, что изменение глубины рельефа копии дифракционной решетки неизбежно приведет к уменьшению дифракционной эффективности, но решение данного вопроса требует дальнейшего изучения.

Для обеспечения аналогичных свойств композиции ОКМ необходимо использовать адгезив - 1\%-раствор 3-триметоксисилил пропилметакрилата (TMSPMA) в смеси этиловый спирт-вода (1:1 по объему). Наносить адгезив на стекло лучше на центрифуге (скорость вращения порядка $500 \mathrm{~s}^{-1}$, время нанесения $1 \mathrm{~min}$ ) или распылением, после чего стекло необходимо прогреть при температуре $100^{\circ} \mathrm{C}$ в течение $3 \mathrm{~min}$.

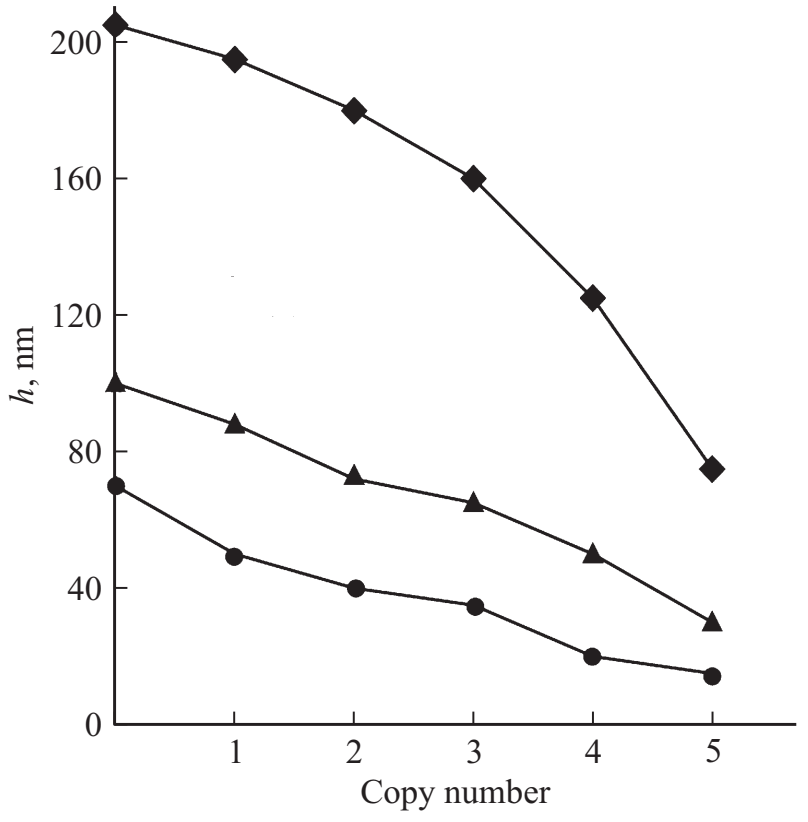

Рис. 1. Глубина поверхностного рельефа полимерных копий, полученных с одной мастер-детали.

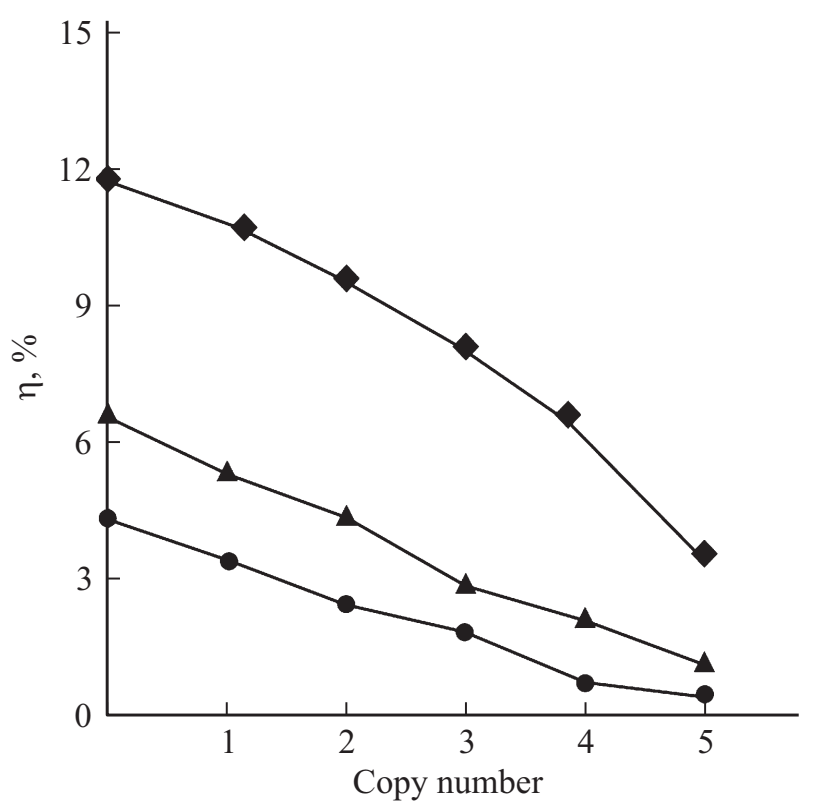

Рис. 2. Зависимость дифракционной эффективности от глубины поверхностного рельефа для различных полимерных копий.

Для оценки эффективности копирования с помощью полимерной композиции ОКМ с одной и той же мастердетали с частотой штрихов $1450 \mathrm{~mm}^{-1}$ и различной глубиной рельефа (порядка 70, 100 и $240 \mathrm{~nm}$ ) были поочередно получены 5 полимерных копий, глубина поверхностного рельефа которых представлена на рис. 1, $a$ дифракционная эффективность на рис. 2.

На рис. 1 видно, что для первых трех копий наблюдается уменьшение глубины рельефа практически в 1.5 ра- 
за по сравнению с исходной структурой, для четвертой копии глубина уменьшается в 2 раза, а для пятой - уже в 3. Значение 0 на оси абсцисс соответствует глубине рельефа мастер-детали.

Дифракционная эффективность первых трех копий отличается не более, чем в 1.3 раза от номинального значения (мастер-детали), у четвертой копий - в 1.6 раза меньше, а для пятой - более чем в 2 раза. Таким образом, на основании значений глубины рельефа и дифракционной эффективности можно сделать вывод, что с одной мастер-детали с помощью композиции ОКМ целесообразно делать не более 3 полимерных копий.

\section{Заключение}

Результаты проведенных исследований показали возможность копирования дифракционных решеток с частотой штрихов $1450 \mathrm{~mm}^{-1}$, полученных на слое фоторезиста, на стеклянные подложки с помощью полимерной композиции ОКМ. Осуществлена оптимизация режимов копирования (определено время экспонирования для толщины полимерной основы до $1 \mathrm{~mm}$, подобран адгезив), что позволило получить рельефно-фазовые дифракционные решетки на световодных подложках с глубиной поверхностного рельефа от 30 до $200 \mathrm{~nm}$, сопоставимой с исходной структурой, полученной в слоях фоторезиста, и дифракционной эффективностью, отличающейся не более чем в 1.2 раза от номинального значения.

\section{Конфликт интересов}

Авторы заявляют, что у них нет конфликта интересов.

\section{Список литературы}

[1] Kovalev M.S., Krasin G.K., Odinokov S.B., Solomashenko A.B., Zlokazov E.Yu. // Opt. Express. 2019. V. 27. P. 1563. doi 10.1364/OE.27.001563

[2] Korolkov V.P., Poleshchuk A.G., Nasyrov R.K. // Proc. SPIE. 2014. V. 9283. P. 928302. doi 10.1117/12.2073301

[3] Одиноков С.Б., Сагателян Г.Р., Ковалёв М.С., Соломашенко А.Б., Дроздова Е.А. // Компьютерная оптика. 2013. T. 37. № 3. C. 341.

[4] Ручка П.А., Вереникина Н.М., Гриценко И.В., Злоказов Е.Ю., Ковалев М.С., Красин Г.К., Одиноков С.Б., Сцепуро Н.Г. // Опт. спектр. 2019. Т. 127. В. 4. С. 563. doi 10.21883/OS.2019.10.48358.172-19; Ruchka P.A., Verenikina N.M., Gritsenko I.V., Zlokazov E.Yu., Kovalev M.S., Krasin G.K., Odinokov S.B., Stsepuro N.G. // Opt. Spectrosc. 2019. V. 127. P. 618. doi 10.1134/S0030400X19100230

[5] Kress B.C. // Proc. SPIE. 2019. V. 11062. P. 110620J. doi $10.1117 / 12.2527680$

[6] Levola T. // J. Soc. Inform. Display. 2012. V. 14. N 5. P. 467. doi 10.1889/1.1828693

[7] Solomashenko A.B., Odinokov S.B., Markin V.V., Kuznetsov A.S., Drozdova E.A. // Proc. SPIE. 2013. V. 8776. P. 87760Q. doi 10.1117/12.2017150
[8] Iwata F., Tsujiuchi J. // Appl. Opt. 1974. V. 13. P. 1327-1336. doi 10.1364/AO.13.001327

[9] Бабкин О.Э., Жданова А.В., Ильина В.В., Михайлов В.Н. // Мир техники кино. 2014. Т. 33. № 3. С. 32.

[10] Ахметов М.М., Гайнутдинов И.С., Иванов В.П., Лукашевич Я.К., Лукин А.В., Мельников А.Н., Могилюк И.А., Никаноров Н.Ю., Саттаров Ф.А. Технологии изготовления элементов дифракционной и асферической оптики. [Электронный ресурс] Режим доступа: http://www.ruoptics.com/vedomosti-russkogo- opticheskogoobshchestva-no3-2018-g 